\title{
Clockwise Torque of Sliding Hip Screws: Is There a Right Side?
}

\author{
Franka S. Würdemann, MD, ${ }^{a}$ Rudolf W. Poolman, MD, PhD, FACS, ${ }^{b}$ Pieta Krijnen, PhD, ${ }^{a}$ \\ Sofia Bzovsky, MSc, ${ }^{c}$ Sheila Sprague, PhD,$^{c, d}$ Bart L. Kaptein, PhD, ${ }^{b}$ Johannes H. Hegeman, MD, PhD, ${ }^{e}$ \\ Emil H. Schemitsch, MD, FRCSC, ${ }^{f}$ Mohit Bhandari, MD, PhD, FRCSC, ${ }^{c, d}$ Marc Swiontkowski, MD, ${ }^{g}$ \\ and Inger B. Schipper, MD, PhD, FACS a on behalf of the Dutch Hip Fracture Audit Group and FAITH \\ Investigators
}

\begin{abstract}
Objectives: This study evaluated whether patients with a left-sided femoral neck fracture (FNF) treated with a sliding hip screw (SHS) had a higher implant failure rate than patients treated for a right-sided FNF. This was performed to determine the clinical relevance of the clockwise rotational torque of the femoral neck lag screw in a SHS, in relation to the rotational stability of left and right-sided FNFs after fixation.
\end{abstract}

Methods: Data were derived from the FAITH trial and Dutch Hip Fracture Audit (DHFA). Patients with a FNF, aged $\geq 50$, treated with a SHS, with at least 3-month follow-up data available, were included. Implant failure was analyzed in a multivariable logistic regression model adjusted for age, sex, fracture displacement, prefracture living setting and functional mobility, and American Society for Anesthesiologists Class.

Accepted for publication August 11, 2020.

From the ${ }^{\mathrm{a} D e p a r t m e n t ~ o f ~ T r a u m a ~ S u r g e r y, ~ L e i d e n ~ U n i v e r s i t y ~ M e d i c a l ~ C e n t e r, ~ L e i d e n, ~ T h e ~ N e t h e r l a n d s ; ~}{ }^{\mathrm{b}}$ Department of Orthopaedic and Trauma Surgery, Leiden University Medical Center, Leiden, The Netherlands; ' Division of Orthopaedics, Department of Surgery, McMaster University, Hamilton, ON, Canada; ${ }^{\mathrm{d}}$ Department of Health Research Methods, Evidence, and Impact, McMaster University, Hamilton, ON, Canada; ${ }^{\mathrm{e}}$ Department of Trauma Surgery, Ziekenhuisgroep Twente, Almelo-Hengelo, The Netherlands; ${ }^{\mathrm{f}}$ Department of Surgery, University of Western Ontario, London, ON, Canada; and ${ }^{\mathrm{g}}$ Department of Orthopaedic Surgery, University of Minnesota, Minneapolis, MN.

All authors made substantial contributions to the design of the study, and/or the analysis and interpretation of the work, did draft or revise the manuscript. All authors gave final approval of the version to be published and are therefore accountable for the accuracy and integrity of this study.

The FAITH trial was supported by research grants from the Canadian Institutes of Health Research (MOP-106630 and MCT-87771), National Institutes of Health (1R01AR055267-01A1), Stichting NutsOhra (SNO-T-0602-43), the Netherlands Organisation for Health Research and Development (80-82310-97-11032), Physicians' Services Incorporated. M. Bhandari was also funded, in part, through the Early Research Award Program which provided funding for this study and by a Canada Research Chair in Musculoskeletal Trauma which is unrelated to this study (McMaster University, Hamilton, ON, Canada). The FAITH trial was also supported by the National Institute of Arthritis and Musculoskeletal and Skin Diseases of the National Institutes of Health under Award Number R01AR055267-01A1. The content is solely the responsibility of the authors and does not necessarily represent the official views of the National Institutes of Health. Research reported in this publication was also supported by The County Durham \& Tees Valley Comprehensive Local Research Network which operates as part of the National Institute for Health Research Comprehensive Clinical Research Network in England. The funding sources had no role in design or conduct of the study; the collection, management, analysis, or interpretation of the data or the preparation, review, or approval of the manuscript. The Dutch Hip Fracture Audit (DHFA) Group did not receive any funding.

R. W. Poolman reports board or committee member for the Dutch Orthopaedic Association, research support from Lima, and research support from Link Orthopaedics, outside the submitted work. S. Sprague reports editorial or governing board for BMS Women's Health, employment from Global Research Solutions Inc., and employment from McMaster University, outside the submitted work. B. L. Kaptein reports board or committee member for the International Radiostereometry Society, outside the submitted work. Dr. Hegeman reports research support from the AO foundation, board or committee member for the Dutch Hip Fracture Audit, board or committee member for the Dutch Trauma Society, and editorial or governing board for the Geriatric Orthopaedic Surgery \& Rehabilitation, outside the submitted work. E. H. Schemitsch reports personal fees from Acumed, LLC, personal fees from Amgen Co, research support from Biocomposites, board or committee member for the Canadian Orthopaedic Association, personal fees from DePuy, board or committee member for the Hip Society, board or committee member for the International Society for Fracture Repair, personal fees from ITS, editorial or governing board for the Journal of Orthopaedic Trauma, board or committee member for the Orthopaedic Trauma Association, editorial or governing board for the Orthopaedic Trauma Association International, board or committee member for the Osteosynthesis and Trauma Care Foundation, personal fees from Pentopharm, personal fees from Sanofi-Aventis, personal fees from Saunders/Mosby-Elsevier, personal fees from Smith \& Nephew, personal fees from Springer, personal fees from Stryker, personal fees from Swemac, and personal fees from Zimmer, outside the submitted work. M. Bhandari reports research support from Acumed, LLC, research support from Aphria, research support from Ferring Pharmaceuticals, research support and personal fees from PendoPharma, and research support and personal fees from Sanofi-Aventis, outside the submitted work. M. Swiontkowski reports board or committee member for the American Orthopaedic Association, consultant to the Minnesota Board of Medical Practice, editorial or governing board and publishing royalties, financial or material support for the Journal of Bone and Joint Surgery-American, publishing royalties, financial or material support from Saunders/Mosby-Elsevier, publishing royalties, financial or material support from Wolters Kluwer Health-Lippincott Williams \& Wilkins, outside the submitted work. I. B. Schipper reports editorial or governing board for the British Journal of Surgery, editorial or governing board for current trauma reports, editorial or governing board for injury, and president of the board of AO Netherlands, outside the submitted work. The remaining authors report no conflict of interest.

Reprints: Franka S. Würdemann, MD, Department of Trauma Surgery, Leiden University Medical Center, Leiden, The Netherlands (e-mail: f.s.wuerdemann@, lumc.nl).

Copyright (C) 2020 Wolters Kluwer Health, Inc. All rights reserved.

DOI: 10.1097/BOT.0000000000001934

S76 I www.jorthotrauma.com

J Orthop Trauma • Volume 34, Number 11 Supplement, November 2020 
Results: One thousand seven hundred fifty patients were included, of which 944 (53.9\%) had a left-sided and $806(46.1 \%)$ a right-sided FNF. Implant failure occurred in 60 cases $(3.4 \%)$, of which 31 were left-sided and 29 right-sided. No association between fracture side and implant failure was found [odds ratio (OR) for left vs. right 0.89 , $95 \%$ confidence interval (CI) $0.52-1.52]$. Female sex (OR 3.02, CI: 1.62-6.10), using a mobility aid (OR 2.02, CI 1.01-3.96) and a displaced fracture (OR 2.51, CI: 1.44-4.42), were associated with implant failure.

Conclusions: This study could not substantiate the hypothesis that the biomechanics of the clockwise screw rotation of the SHS contributes to an increased risk of implant failure in left-sided FNFs compared with right-sided fractures.

Key Words: femoral neck fracture, implant failure, sliding hip screw, side, left, right, clockwise torque, rotational stability, biomechanics

(J Orthop Trauma 2020;34:S76-S80)

\section{INTRODUCTION}

Despite the fact that fixation techniques have been modernized over the years, failure rates in femoral neck fractures (FNFs), especially in the displaced ones, remain as high as $20 \%-40 \% .^{1,2}$ Some of these failures can be attributed to avascular necrosis of the femoral head, whereas in others, fracture collapse or true implant failure cause a breakdown of the bone-implant construct. ${ }^{1-4}$ In many cases, however, it is not clear which of the underlying factors contribute most to construct failure. It is, therefore, not without reason that the FNF is still described as the "unsolved" fracture.,

Patient and fracture-related factors that influence failure rates have been thoroughly examined. The fracture type or pattern seems to be one of the most critical determinants of the failure of the bone-implant construct. ${ }^{7,8}$ Could it be, despite all the research on the topic, that we are overlooking or underestimating the influences of the biomechanics of the implant?

A study using radiostereometric analysis (RSA) showed that right-sided trochanteric fractures seemed to be more stable compared with left-sided trochanteric fractures after fixation with a sliding hip screw (SHS). ${ }^{9}$ It was hypothesized that the clockwise rotational torque in the sagittal plane during placement of the lag screw may contribute to a potentially more unstable construct in left-sided trochanteric fractures compared with right-sided fractures. ${ }^{10}$ It is during the screw insertion that clockwise rotational torque is imparted to the head-neck fragment, which in left-sided trochanteric fractures may cause flexion in the hip and extension of the fracture site, leading to a potentially unstable construct. ${ }^{10}$ These biomechanical theories and findings suggest that the risk of implant failure is higher in left-sided trochanteric fractures fixed with a SHS compared with right-sided trochanteric fractures. A similar biomechanical theory has been described for lateral FNFs. ${ }^{11}$ To the best of our knowledge, no evidence or theories have yet been published to support or deny this suggestion for FNFs.

Although there are obvious biomechanical differences between trochanteric hip fractures and FNFs, we hypothesize a similar instability in the bone-implant construct in left-sided FNFs compared with right-sided FNFs. Not only during insertion, but also during cyclic loading, eccentric forces may result in the femoral head and neck rotating around the lag screw. ${ }^{12,13}$ As the patterns of the resulting torques at the fracture site are opposite for left and right hips, resistance to these cyclic torques by the screw thread is also opposite as the screw thread is always clockwise. A dorsocaudally applied load over the left femoral head may therefore cause micromovement with backward rotation of the femoral head and subsequent loosening of the implant from the head. ${ }^{14-16}$ To illustrate this, a comparison could be made with the peddles on a bicycle. The left and right peddle both move in a forward cyclic manner while cycling and, equal to walking, go through a loaded and nonloaded phase. Opposed to the right peddle with a "normal" clockwise thread attachment, a counter-clockwise thread is used in the attachment of the left peddle to prevent loosening of the left peddle (and eventually falling off).

The primary objective of this pre-planned analysis was to determine whether patients with a left-sided FNF have a higher failure rate of SHS fixation than patients with a FNF on their right side.

\section{MATERIALS AND METHODS}

\section{Data Sources}

Data were derived from the FAITH trial and The Dutch Hip Fracture Audit (DHFA). ${ }^{17,18}$ The FAITH trial was a multicenter, concealed randomized controlled trial comparing fixation of FNF with cancellous screws versus a SHS. The current study concerns a preplanned secondary analysis of patients of the SHS fixation arm of the study. The DHFA is the Dutch nationwide multidisciplinary hip fracture audit in which all patients with a hip fracture have been registered since 2016. It is part of the Dutch Institute for Clinical Auditing (DICA).

\section{Patients}

Patients aged $\geq 50$ years, diagnosed with a FNF (OTA/ AO 31B) treated with a SHS, and with 3 months follow-up, data available were included in this study. ${ }^{19}$ Excluded were patients with periprosthetic fractures or pathological fractures and patients with no prefracture functional mobility.

\section{Outcome Parameters}

The primary outcome parameter was implant failure. In the FAITH trial, implant failure was defined as revision surgery because of loosening or breakage of the implant or other reasons (mostly screw cut-out). Implant failure in the DHFA was defined as revision surgery because of migration of the implant, loosening, or the implant breaking out.

\section{Statistical Analysis}

Variables recorded as "unknown" were recorded as missing. Missing values were assumed to be missing at random and were, therefore, left out from the analysis. The independent sample $t$ test was used for comparison of continuous 
normally distributed variables, the Mann-Whitney $U$ test for non-normally distributed variables, and the $\chi^{2}$ test for categorical variables. The odds ratio (OR) with $95 \%$ confidence interval (CI) for the risk of implant failure for left-sided fractures versus right-sided fractures was calculated using multivariable logistic regression analysis with adjustment for age, fracture displacement (displaced or undisplaced), prefracture living situation (institutionalized or not institutionalized), prefracture functional mobility (using a walking aid or able to ambulate without a walking aid), and American Society for Anesthesiologists (ASA) Class (Class $1 / 2$ or $3 / 4 / 5$ ). $P$-values $<0.05$ were regarded as statistically significant. Statistical analysis was performed with R Studio Version 1.1.456 (R Foundation for Statistical Computing, Vienna, Austria). ${ }^{20}$

\section{RESULTS}

In total, 1750 patients (1215 from the DHFA and 535 from the FAITH data set) fulfilled the inclusion criteria and were analyzed. Baseline characteristics per data source are shown in Table 1. The fracture was left-sided in $944(53.9 \%)$ patients, and $806(46.1 \%)$ patients had a right-sided FNF. The mean age was 70.7 years (SD 12.6), 57.1\% were women, who were shown to have significantly more left-sided fractures compared with men left-sided fractures $(54.0 \%$ vs. $46.0 \%$, $P=0.02)$. Sixty-nine percent of patients were ASA Class 1 or 2. Before the fracture, $94.9 \%$ were not institutionalized, and most patients did not use a mobility aid (80.9\%). Of all fractures, 681 were displaced $(38.9 \%)$. There was a small but statistically significant difference between the data sets for most baseline characteristics.

Implant failure within the first 3 months occurred in 60 patients $(3.4 \%)$. The incidence of implant failure was higher in the FAITH trial than in the DHFA $(7.9 \%$ vs. $1.5 \%, P<$ 0.01; Table 1). The implant failure rates in left-sided hips (31/ $944=3.3 \%)$ and in right-sided hips $(29 / 806=3.6 \%)$ were similar. Fifty-five percent of implant failures occurred in FNFs which were initially displaced.

No significant association between the fracture side and implant failure was found. The OR of implant failure in leftsided hips compared with right-sided hips was 0.91 (95\% CI: $0.54-1.53, P=0.72)$ in the univariable analysis and 0.89 (95\% CI: $0.52-1.53, P=0.66)$ in the multivariable analysis (Table 2).

Female sex (univariable analysis: OR 2.54, 95\% CI 1.42-4.83, $P<0.01$; multivariable analysis: OR 3.02, 95\% CI $1.52-6.10, P<0.01$ ), using a mobility aid before the fracture (univariable analysis: OR 2.01, 95\% CI 1.11-3.51, $P=0.02$; multivariable analysis: OR $2.02,95 \%$ CI $1.01-3.96$, $P=0.04$ ), and having a displaced fracture (univariable analysis: OR 1.97, 95\% CI 1.17-3.32, $P=0.01$; multivariable analysis: OR $2.51,95 \%$ CI 1.44-4.42, $P<0.01$ ) were associated with implant failure (Table 2).

\section{DISCUSSION}

To the best of our knowledge, this is the first study that evaluates the difference in fracture fixation stability using the SHS in left-sided and right-sided FNFs. In our combined study group of 1750 patients with a FNF treated with a SHS, 3.4\% had a failure of the bone-implant construct. No association between fracture side and implant failure was found.

Two studies performed by Mohan et $\mathrm{al}^{10}$ and Van Embden et $\mathrm{al}^{9}$ mentioned a possible difference in rotational stability in left-sided and right-sided trochanteric fractures. As a response, Pervez and Parker ${ }^{21}$ reviewed the incidence of screw cut-out of 1147 SHS in trochanteric fractures and did not find a difference in left-sided and right-sided fractures. Although the biomechanical theory for a potential difference in implant stability between left-sided and right-sided hips seems plausible, we could not find any biomechanical studies on leftsided and right-sided differences in FNFs. Also, no additional evidence was found from 2 publications on large randomized hip fracture trials investigating implant failure of SHS because these did not include fracture side as a confounding factor in

TABLE 1. Baseline Characteristics of Included Patients, per Data Source

\begin{tabular}{|c|c|c|c|c|}
\hline & Total & DHFA & FAITH & $P^{*}$ \\
\hline Total & 1750 & 1215 & 535 & \\
\hline Age, mean (SD) & $\begin{array}{c}70.7 \\
(12.6)\end{array}$ & $\begin{array}{c}70.2 \\
(12.9)\end{array}$ & $\begin{array}{c}71.9 \\
(12.0)\end{array}$ & 0.02 \\
\hline \multicolumn{5}{|l|}{ Sex, n (\%) } \\
\hline Male & $\begin{array}{c}751 \\
(42.9)\end{array}$ & $\begin{array}{c}539 \\
(44.4)\end{array}$ & $\begin{array}{c}212 \\
(39.6)\end{array}$ & 0.07 \\
\hline Female & $\begin{array}{c}999 \\
(57.1)\end{array}$ & $\begin{array}{c}676 \\
(55.6)\end{array}$ & $\begin{array}{c}323 \\
(60.4)\end{array}$ & \\
\hline \multicolumn{5}{|c|}{$\begin{array}{l}\text { Prefracture living situation, } \\
\mathrm{n}(\%)\end{array}$} \\
\hline Home & $\begin{array}{l}1561 \\
(94.9)\end{array}$ & $\begin{array}{l}1056 \\
(95.1)\end{array}$ & $\begin{array}{c}505 \\
(94.4)\end{array}$ & 0.60 \\
\hline Institution & $84(5.1)$ & $54(4.9)$ & $30(5.6)$ & \\
\hline \multicolumn{5}{|c|}{ Prefracture mobility, n (\%) } \\
\hline Without aid & $\begin{array}{c}1347 \\
(80.9)\end{array}$ & $\begin{array}{c}931 \\
(82.4)\end{array}$ & $\begin{array}{c}416 \\
(77.8)\end{array}$ & 0.03 \\
\hline With aid & $\begin{array}{c}318 \\
(19.1)\end{array}$ & $\begin{array}{c}199 \\
(17.6)\end{array}$ & $\begin{array}{c}119 \\
(22.2)\end{array}$ & \\
\hline \multicolumn{5}{|l|}{ ASA class, $n(\%)$} \\
\hline 1,2 & $\begin{array}{c}1180 \\
(68.6)\end{array}$ & $\begin{array}{c}840 \\
(70.8)\end{array}$ & $\begin{array}{c}340 \\
(63.6)\end{array}$ & $<0.01$ \\
\hline 3,4 , and 5 & $\begin{array}{c}541 \\
(31.4)\end{array}$ & $\begin{array}{c}346 \\
(29.2)\end{array}$ & $\begin{array}{c}195 \\
(36.4)\end{array}$ & \\
\hline \multicolumn{5}{|c|}{ Displacement, n (\%) } \\
\hline Undisplaced & $\begin{array}{c}1069 \\
(61.1)\end{array}$ & $\begin{array}{c}714 \\
(58.8)\end{array}$ & $\begin{array}{l}355 \\
(66.4)\end{array}$ & $<0.01$ \\
\hline Displaced & $\begin{array}{c}681 \\
(38.9)\end{array}$ & $\begin{array}{c}501 \\
(41.2)\end{array}$ & $\begin{array}{c}180 \\
(33.6)\end{array}$ & \\
\hline \multicolumn{5}{|c|}{ Fracture side, n (\%) } \\
\hline Right & $\begin{array}{c}806 \\
(46.1)\end{array}$ & $\begin{array}{c}551 \\
(45.3)\end{array}$ & $\begin{array}{c}255 \\
(47.7)\end{array}$ & 0.40 \\
\hline Left & $\begin{array}{c}944 \\
(53.9)\end{array}$ & $\begin{array}{c}664 \\
(54.7)\end{array}$ & $\begin{array}{c}280 \\
(52.3)\end{array}$ & \\
\hline \multicolumn{5}{|c|}{ Implant failure, n (\%) } \\
\hline No & $\begin{array}{c}1690 \\
(96.6)\end{array}$ & $\begin{array}{c}1197 \\
(98.5)\end{array}$ & $\begin{array}{c}493 \\
(92.1)\end{array}$ & $<0.01$ \\
\hline Yes & $60(3.4)$ & $18(1.5)$ & $42(7.9)$ & \\
\hline
\end{tabular}

*Dutch Hip Fracture Audit (DHFA) versus FAITH trial.

$\mathrm{SD}$, standard deviation. 
TABLE 2. Risk of Implant Failure of FNFs, Univariable, and Multivariable Logistic Regression Analysis

\begin{tabular}{|c|c|c|c|c|}
\hline & \multicolumn{2}{|c|}{ Univariable Analysis } & \multicolumn{2}{|c|}{ Multivariable Analysis } \\
\hline & OR $(95 \%$ CI $)$ & $P$ & OR $(95 \%$ CI $)$ & $P$ \\
\hline \multicolumn{5}{|l|}{ Side } \\
\hline Left vs. right & $0.91(0.54-1.53)$ & 0.72 & $0.89(0.52-1.53)$ & 0.66 \\
\hline Age & $1.01(0.99-1.02)$ & 0.19 & $1.00(0.98-1.02)$ & 0.76 \\
\hline \multicolumn{5}{|l|}{ Sex } \\
\hline Female vs. male & $2.54(1.42-4.83)$ & $<0.01$ & $3.02(1.52-6.10)$ & $<0.01$ \\
\hline \multicolumn{5}{|l|}{ Prefracture living situation } \\
\hline Institution vs. home & $1.34(0.40-3.38)$ & 0.58 & $1.21(0.34-3.35)$ & 0.74 \\
\hline \multicolumn{5}{|l|}{ Prefracture mobility } \\
\hline With vs. without aid & $2.01(1.11-3.51)$ & 0.02 & $2.02(1.01-3.96)$ & 0.04 \\
\hline \multicolumn{5}{|l|}{ ASA class } \\
\hline 3,4, or 5 vs. 1 or 2 & $1.18(0.68-2.01)$ & 0.54 & $1.04(0.55-1.92)$ & 0.89 \\
\hline \multicolumn{5}{|l|}{ Displacement } \\
\hline Displaced vs. undisplaced & $1.97(1.17-3.32)$ & 0.01 & $2.51(1.44-4.42)$ & $<0.01$ \\
\hline
\end{tabular}

CI, confidence interval; OR, odds ratio.

their analyses. ${ }^{17,22}$ From these studies we may conclude that if present, rotational instability caused by the clockwise torqued screw did not have clinical relevance in increased implant failure in left-sided trochanteric fractures. Our study shows that this conclusion also seems to apply to FNFs.

The implant failure rate found in this study was 3.4\%. Other studies found overall complication rates of SHS varying between $5.2 \%$ and $16.7 \%$. Tsang et $\mathrm{al}^{23}$ reported a surgical revision rate for mechanical causes of $2.8 \%$. The difference in implant failure rate between the FAITH trial data $(7.9 \%)$ and the DHFA data $(1.5 \%)$ may be explained by an underestimation of the implant failure rate because of the retrospective design of the DHFA registry, whereas the data derived from the FAITH trial were prospectively collected and thus of better quality. If implant failures were missed in the DHFA, it is likely this would have occurred equally in right-sided and left-sided hip fractures and would therefore not have biased the results of our study. The differences in baseline characteristics of the patients from both data sources were small and of little clinical relevance.

Factors increasing the risk of implant failure have been thoroughly studied by several investigators. Failure because of nonunion or malunion is more often seen in displaced fractures (eg, Garden type 3 and 4) and high shear angle fractures (eg, Pauwels type 3). ${ }^{8,24-26}$ In our study, fracture displacement confirmed a statistically significant association with implant failure.

Associations of implant failure with other previously found risk factors such as fracture pattern, bone quality, $3,27,28$ accuracy of the fracture reduction and implant positioning, 8,29 body mass index, smoking, concomitant injuries and comorbidities, and therapy compliance (in weight-bearing) of the patient ${ }^{5,7}$ could not be substantiated in our study because these factors were not documented in both the data sources. Some of these factors were collected in one of the data sources, but not the other, or vice versa. Other factors described in the literature that may contribute to fixation failure are age and female sex. In our study, we have found that female patients and patients using mobility aid before the fracture had a significantly higher risk of implant failure. These findings are in line with previous studies.

The strength of this study is the large number of patients included from both a clinical trial and a national registry, so that the study group is representative of the general FNF patient population. A limitation of the combined data sets was that some information was lost because variables were classified differently. For instance, the fractures in the FAITH data set were described according to the Pauwels and Garden classification but were analyzed as displaced or undisplaced to match the fracture classification used in the DHFA. Also, data of only the first 3 months of the available 24-month follow-up in the FAITH data set was used to match the length of follow-up to that in the DHFA data set. However, implant failure of SHS mostly occurred in the first several months postsurgery, ${ }^{17}$ presumably when a patient starts weight-bearing. The number of implant failures occurring between 3 and 24 months in the FAITH data set was too low to be analyzed separately. We considered the 3-month follow-up to be sufficient to evaluate the difference in implant failure in left-sided and right-sided SHS.

Because of the retrospective design of this study, only variables collected in both the FAITH trial and the DHFA registry could be used in the analysis. Thus, we could not correct for all risk factors known to be related to implant failure, such as bone density and body mass index. ${ }^{7}$ Details on the quality of the reduction, the quality and technique of the fixation (ie, if an antirotation K-wire was used while inserting the screw), the tip apex distance, and screw position were not available nor did the data contain details on the exact type of implant.

\section{CONCLUSIONS}

The results of this study could not substantiate the hypothesis that the biomechanics of the clockwise screw rotation of the SHS contributes to an increased risk of failure of the implant in left-sided FNFs compared with right-sided FNFs. 


\section{ACKNOWLEDGMENTS}

The authors thank the Dutch Hip Fracture Audit (DHFA) Group Investigators (A. J. Arends, B. J. Blom, M. van Eijk, M. J. Heetveld, M. van Heijl, M. C. Luyten, B. G. Schutte, M. S. Slee-Valentijn, S. C. Voeten, and A. H. Calf) and the FAITH Investigators (http://links.lww.com/JOT/B249).

\section{REFERENCES}

1. Queally JM, Harris E, Handoll $\mathrm{HHG}$, et al. Intramedullary nails for extracapsular hip fractures in adults. Cochrane Database Syst Rev. 2014;9:CD004961.

2. Lu-Yao GL, Keller RB, Littenberg B, et al. Outcomes after displaced fractures of the femoral neck. A meta-analysis of one hundred and six published reports. J Bone Joint Surg Am. 1994;76:15-25.

3. Heetveld MJ, Raaymakers ELFB, van Eck-Smit BL, et al. Internal fixation for displaced fractures of the femoral neck. Does bone density affect clinical outcome? J Bone Joint Surg Br. 2005;87:367-373.

4. Bhandari M, Devereaux PJ, Swiontkowski MF, et al. Internal fixation compared with arthroplasty for displaced fractures of the femoral neck: a meta-analysis. J Bone Joint Surg Am. 2003;85:1673-1681.

5. Estrada LS, Volgas DA, Stannard JP, et al. Fixation failure in femoral neck fractures. Clin Orthop Relat Res. 2002;399:110-118.

6. Li M, Cole PA. Anatomical considerations in adult femoral neck fractures: how anatomy influences the treatment issues? Injury. 2015;46:453-458.

7. Sprague S, Schemitsch EH, Swiontkowski M, et al. Factors associated with revision surgery after internal fixation of hip fractures. J Orthop Trauma. 2018;32:223-230.

8. Schep NWL, Heintjes RJ, Martens EP, et al. Retrospective analysis of factors influencing the operative result after percutaneous osteosynthesis of intracapsular femoral neck fractures. Injury. 2004;35:1003-1009.

9. van Embden D, Stollenwerck GANL, Koster LA, et al. The stability of fixation of proximal femoral fractures. Bone Joint J. 2015;97-B:391-397.

10. Mohan R, Karthikeyan R, Sonanis SV. Dynamic hip screw: does side make a difference? Effects of clockwise torque on right and left DHS. Injury. 2000;31:697-699.

11. Collinge CA, Mir H, Reddix R. Fracture morphology of high shear angle "Vertical" femoral neck fractures in young adult patients. J Orthop Trauma. 2014;28:270-275.

12. Den Hartog BD, Bartal E, Cooke F. Treatment of the unstable intertrochanteric fracture: effect of the placement of the screw, its angle of insertion, and osteotomy. J Bone Joint Surg Am. 1991;73:726-733.

13. Kawaguchi S, Sawada K, Nabeta Y. Cutting-out of the lag screw after internal fixation with the Asiatic gamma nail. Injury. 1998;29:47-53.
14. Anderson AE, Ellis BJ, Maas SA, et al. Effects of idealized joint geometry on finite element predictions of cartilage contact stresses in the hip. $J$ Biomech. 2010;43:1351-1357.

15. Hoechel S, Alder M, Wirz D, et al. The human hip joint and its long-term load intake - how X-ray density distribution mirrors bone strength. HIP Int. 2013;23:583-589.

16. Brown TD, Shaw DT. In vitro contact stress distributions in the natural human hip. J Biomech. 1983;16:373-384.

17. Fixation using Alternative Implants for the Treatment of Hip fractures (FAITH) Investigators, Nauth A, Creek AT, et al. Fracture fixation in the operative management of hip fractures (FAITH): an international, multicentre, randomised controlled trial. Lancet. 2017; 389:1519-1527.

18. Voeten SC, Arends AJ, Wouters MWJMJM, et al. The Dutch Hip Fracture Audit: evaluation of the quality of multidisciplinary hip fracture care in The Netherlands. Arch Osteoporos. 2019;14:28.

19. Meinberg E, Agel J, Roberts C, et al. Fracture and dislocation classification compendium-2018. J Orthop Trauma. 2018;32:S1-S10.

20. Rstudio Team. RStudio: Integrated Development for R. RStudio, Inc. Boston, MA: RStudio, 2019.

21. Pervez H, Parker MJ. Dynamic hip screw: does side make a difference? Effects of clockwise torque on the right and left DHS (multiple letters) [1]. Injury. 2002;33:93-94.

22. Parker MJ. Sliding hip screw versus intramedullary nail for trochanteric hip fractures; a randomised trial of 1000 patients with presentation of results related to fracture stability. Injury. 2017;48:2762-2767.

23. Tsang STJ, Aitken SA, Golay SK, et al. When does hip fracture surgery fail? Injury. 2014;45:1059-1065.

24. Garden RS. Low-angle fixation in fractures of the femoral neck. $J$ Bone Joint Surg Br. 1961;43-B:647-663.

25. Meinberg E, Agel J, Roberts C, et al. Fracture and Dislocation Classification Compendium-2018. J Ortho Trauma. 2018; 32 Suppl 1; S1-S170.

26. Pauwels F. Der schenkelhalsbruch: ein mechanisches problem. Br J Surg. 1936;23:874

27. Viberg B, Ryg J, Overgaard S, et al. Low bone mineral density is not related to failure in femoral neck fracture patients treated with internal fixation. Acta Orthop. 2014;85:60-65.

28. Kain MS, Marcantonio AJ, Iorio R. Revision surgery occurs frequently after percutaneous fixation of stable femoral neck fractures in elderly patients. Clin Orthop Relat Res. 2014;472:4010-4014.

29. Haynes RC, Pöll RG, Miles AW, et al. Failure of femoral head fixation: a cadaveric analysis of lag screw cut-out with the gamma locking nail and AO dynamic hip screw. Injury. 1997;28:337-341. 